\title{
The Influence of Decision Making in Organizational Leadership and Management Activities
}

Nichodemus Obioma Ejimabo*

Wayland Baptist University Fairbanks, Alaska, USA

\begin{abstract}
This study explores the influence of decision making in organizational leadership and management activities that impact creativity, growth and effectiveness, success, and goal accomplishments in current organizations. The purpose of this qualitative critical ethnographic study was focused on identifying the factors influencing success in decision making among organizational leaders and managers in organizations' practices. The qualitative paradigm was used in order to gain in-depth knowledge and understanding of the issues and challenges influencing effectiveness, and success among organizational leadership and managements in business practices. The author being committed and determined to discovering a pattern of meaning through experience, systemic thinking, assessment, and creative analysis used the Kurt Lewin leadership philosophical underpinning approaches of leadership namely: autocratic, democratic, and laissezfaire methods of leadership decision making processes in the context of this study, with the aim of discovering the main factors rather than specific variables and outcomes affecting decision making among business leaders. Approximately, four hundred past and current business executives and managements participated in this study. Data was collected through structured interviews and surveys. The results that emerged from the data indicated that there is a great need for change and improvement in decision making among organizational executives while accommodating technology, diversity, globalization, policy, teamwork, and leadership effectiveness.
\end{abstract}

Keywords:Teamwork; Leadership; Management; Decision-making; Policy; Communication; Organizational growth; Ethics and leadership activities

\section{Introduction}

In general, leadership decision making (LDM) among other qualities and functions of a leader offers an ongoing creativity and important new insights into leadership and management activities in all organizational operations. The purpose of this study was focused on identifying the factors influencing success in decision making among organizational executives, leaders, mangers, and supervisors in organizations' practices. Organization is undoubtedly a systemic network that is both complex and dynamic in nature. In organizations, tough quality and sound decision making are the major element and essence of leadership. The other goal of this work is to discover a scientific break-through which is based on the experience, knowledge, and the skills of the selected participants of this study with the aim of improving quality decision making among leaders and overall accomplishment of organizational goals, objectives, and performance. In this regard and for effectiveness, a leader must have self confidence in order to gather and process information and solve problems. For them a person riddled with self-doubt would never be able to take the necessary actions nor command the respect of others. Leaders must know what decisions to make and keep the interest of all stakeholders involved. Followers will be less committed to the team if the leader doubts their decisions. They must show followers that they are able to acknowledge when they are wrong and move forward to a better solution. In discussing the statement of the problem; bad policy and inconsistence in decisions making are among the major challenges in organizational systems and have created many unresolved problems among leaders and their employees in our current workplace and entire society. The inabilities of some leaders in developing good policy standards, knowledge, basis, protocols, environments, and skill that incorporate support and optimal decision design for their organizations is troubling and have caused the closure of many business in the country due to either law suit or mismanagement. Another significant problem that encouraged this work is the lack of knowledge on how to design positive decision environment, healthy communication skills, and essential tools for leadership decision making in the entire organization. Many leadership practitioners and scholars believed that any organization faced with negative policy and decisions by its leadership and management will continue to fail, their people will be often left to ponder the cause, and that organization would be unproductive in their business while giving way to employees to break the circle for both job performance and goal accomplishment. For instance [1], said, "Authentic leaders exemplify high moral standards, integrity, honesty, and authentic leaders acknowledge their personal limitations and shortcomings, and are therefore less likely to adopt a defensive attitude about organizational problems". Furthermore, creative policy development and decision making among organizational leaders and management are of vital importance to the growth, development, and success of any business establishments. For instance, choosing the best alternative from many alternatives and making a good decision in critical matters and challenging situations is always a good strategy of solving problems in most organizations. Thus, the problem in most organizations is that problems tend to present themselves in non-associated symptoms. And the tendency of organizational members and business executives is often to address symptoms of the problem irrespective of the facts that members may "know" that the problem they are addressing is just a mere symptom. This point contributes among other factors, one of the major loopholes in decision making by managements and organizational leaders. However, being able to see problems from a

*Corresponding author: Nichodemus Obioma Ejimabo, Wayland Baptist University Fairbanks, Alaska, USA, E-mail: nickejimsmith@yahoo.com.

Recieved April 22, 2014; Accepted May 18, 2015; Published May 28, 2015

Citation: Ejimabo NO (2015) The Influence of Decision Making in Organizational Leadership and Management Activities. J Entrepren Organiz Manag 4: 138 doi:10.4172/2169-026X.1000138

Copyright: (c) 2015 Ejimabo NO. This is an open-access article distributed under the terms of the Creative Commons Attribution License, which permits unrestricted use, distribution, and reproduction in any medium, provided the original author and source are credited. 
variety of other perspectives from within the organization allows for a better understanding of the problem [2].

There is a plethora of studies on different topics on organizational leadership and decision making. However, there is a gap in literature particularly on leadership decision making and the variations that exist on the manner, perceptions, skills, and processes used in making decisions.

This qualitative ethnography study was centered on identifying the factors influencing success in decision making among organizational executives, leaders, mangers, and supervisors in organizations' practices and effectiveness. This method allowed the researcher to see and work with the participants from both their natural environment and cultural individual settings. By using this method, the researcher did not seek to conduct full contextual description but rather looked for patterns in meaning as well as similarities and differences that lead to contextualization, categorization and eventual theoretical codes and relationship among concepts that explained this variation. He also examined some leaders' attributes while being determined to provide a framework for helping organizational leaders and executive managers the ability to choose who should make distinct decisions in various critical and challenging situations. This work was designed to discover a concrete, effective, efficient, unambiguous, and useful means to know and use to implement each leadership decision processes that the situation deems fitting well in the company's problems. It was also the hope of the researcher to find a distinct, precise, and concise (separating oranges and apples) way to tailor solutions to fit the needs of the individual employees and employers based on their leadership and learning styles; mission and vision; strategic objectives, and goal accomplishment. A nationwide study of four hundred past and current business executives, leaders, and managements participated in this study and they identified some factors that influenced their decision making in their respective organizations.

This work was also aimed at showing that the establishment and implementation of a proper policy and decisions that will influence the organizational leadership and management must include a review of the existing policies, strategies, and standards to ensure that leaders, managers, supervisors, and employees will continue to achieve an efficient and effective role in both performance management and goals accomplishment in the system. The best approach to lead, and manage an organization effectively is to understand the organization in all its entity, and its growth, success, and goal accomplishments will be based solely on the policy, mission, and vision of the organization. A good understanding and the establishment of sound decisions and policies are very important for organizational leadership activities and reform [3]. Sound decision making in every organization must be for leaders and managers the direct result of knowing their criteria for success, the scope of their choices, and the inherent risk of each alternative [4].

\section{Meaning and Definition of Leadership and Decision Making}

According to [5], the term leadership is a word taken from the common vocabulary and incorporated into the technical vocabulary of a scientific discipline without being precisely redefined. Both leadership and decision making are terms that are seriously considered to be of vital in the operations of any organization, society, and country. These terms have been a major topic of research in both psychology, social sciences, and other disciplines for almost a century and has spawned thousands of empirical and conceptual studies. They have gained the attention of researchers worldwide and are expensive terms with many (different) meanings, definitions, and applications in which case one size does not necessarily fit all. There are almost as many definitions of leadership (and decision making) as there are persons who have attempted to define the concept [6]. Because of their importance, usefulness, and value; many people have tried to define them differently to suit their situation, individual or group interests, positions, perspectives, and circumstances while creating a pattern of meaning as well as maintaining their effectiveness in any organizational activities and practices. While the term "leadership" is associated with influence and the ability to empower, encourage, support, and help others by an individual or group of individuals to accomplish a goal; decision making as a theory is focused exclusively choice and the ability of the leader to select the best alternative from the many options [7]. How to integrate the two processes has emerged as a complex and important issue in the organizational literature [8].

Below are some the ways different scholars had defined the above terms:

- Leadership is a process whereby an individual influences a group of individuals to achieve a common goal [9].

- Leadership is the process of making sense of what people are doing together so that people will understand and be committed [10].

- Leadership is the process of influencing others to understand and agree about what needs to be done and how to do it, and the process of facilitating individual and collective efforts to accomplish shared objectives [5].

- "Leadership is a process of giving purpose (meaningful direction) to collective effort, and causing willing effort to be expended to achieve purpose" [11].

- Decision making is a deliberative and decisive social action, concerned with choosing what to do in the face of a problem $[12,13]$.

- Decision making is a choice from among two or more alternative courses of action, or objects, giving due regard to the advantages and disadvantages of supporting information about each" (http://www.merriam-webster.com/dictionary/decision).

- Leadership decision making is an intendedly rational human choice leading to human action embodying the logic of consequence (March, 1991).

- Decision making is a commitment to action, a discrete and concrete phenomenon driven by rationality [13].

In this study, leadership decision making (LDM) is defined as a dynamic process of choosing from the best different alternatives and associated with the systemic act of making a choice. In organizational worldview, decision making has been a serious educational and organizational issue for many years and had continued to baffle many researchers as they look for creative and effective solution for this profound societal and organizational challenge. Therefore, to understand organizational decision making process, leadership must define what the future should look like, aligns with that vision, and inspire them to make it happen despite the challenges and obstacles involved. Leaders must know how to lead as well as manage, otherwise, without leading as well as managing effectively, today's organizations will face the threat of extinction [14]. Thus, leaders and workers in every organization should be influenced by their policy and decisions while working together to attain strategic goals and objectives. Complexity and other factors or challenges had shown that there is a 
great need for the development and implementation of proper policy by organizational leaders. Basically, some recent studies have shown that decision making has a central role to play in developing and influencing organizational activities. These activities include healthy working environment and trust that helps in developing effective communication and openness in the relationship between employees and management; between superiors and subordinates; between trade union and management; and among workers in the workplace [15].

\section{The Theoretical Framework of Kurt Lewin}

The author used the theoretical framework of psychologist Kurt Lewin methods of leadership behavioral styles and decision making processes in the context of this study, with the aim of using them in discovering the main factors rather than specific variables and outcomes affecting decision making among business leaders. Lewin 's theories of "leadership styles and their effects" in collaboration with colleagues Lippitt and White carried out research relating to the effects of three different leadership styles on active boys' activity group in Iowa1939. His thinking was changing to emphasize social psychological problems. These school-children were assigned to one of three groups with an authoritarian, democratic or laissez-fair leader. The children were then led in an arts and crafts project while researchers observed the behavior of children in response to the different styles of leadership. He is well known for his term "life space" and work on group dynamics, as well as T-groups. Lewin's commitment to applying psychology to the problems of society led to the development of the M.I.T. Research Center for Group Dynamics - "He wanted to reach beyond the mere description of group life and to investigate the conditions and forces which bring about change or resist it" [16].

The Kurt Lewin's three leadership styles or behaviors, described below, influence the leader-follower relationship, group success, group risk-taking, group problem-solving strategies, group morale, and group. The three different leadership styles which are namely; autocratic (authoritative), participative (democratic), and delegative (laissez-faire) are described in (Figure 1).

Although everyone makes decisions on a daily and regular basis, but the clear understanding of the role that authoritarian, democratic, and laissez-faire leadership styles play in groups is vital background for all those interested in leadership, management, and the sociology of social interaction in groups and organizations. While these decisions are made in our personal and professional lives; various factors influence leaders and managers' decisions in their individual workplace. Leaders choose their paths based on their style of decision-making. The above Lewin 's three major leadership styles in Figure 1 was designed to show that it is possible for both leaders and manager of any organization

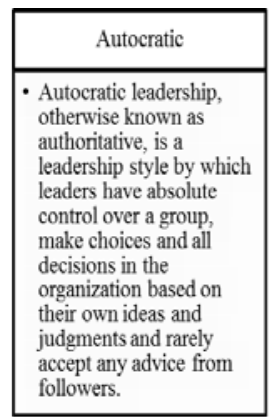

\begin{tabular}{|l|}
\hline \multicolumn{1}{|c|}{ Participative } \\
\hline - Participative, which is \\
also known as democratic \\
is a leadership style that \\
allows and encourages \\
members of the group to \\
share, express their ideas, \\
and take a more \\
participative role in the \\
decision-making process \\
of the organization. \\
\end{tabular}

\begin{tabular}{|l|}
\hline \multicolumn{1}{|c|}{ Delegative } \\
\hline - Laissez-faire leadership, \\
also known as delegative, \\
also known as laissez- \\
faire is a type of \\
leadership style in which \\
leaders by providing the \\
tools and resources \\
needed ( with little \\
guidance) are hands-off \\
and allow group \\
members to make the \\
decisions in their \\
organizations. \\
\hline
\end{tabular}

Figure 1: Kurt Lewin's three major leadership decision making styles. to change their styles, and to be trained to improve their leadership and adopt appropriate management styles for their situation and context [17]. Lewin is now mainly remembered as the originator of the 3-Step model of change [18], and this tends often to be dismissed as outdated [19-24] yet many researchers and leaders still agree that his contribution to our understanding of individual and group behavior and the role these play in organizations and society was enormous and is still relevant in leadership and management practices.

Over the years, the study of organizational behavior has led to a number of useful models for decision making in many businesses. As with decision making and all other organizational issues and challenges, overcoming any kind of small deficiency can help leaders and managers become more dynamic, efficient, and successful in their organizations as well as the society. All groups (employees and employers) must be educated about the relevant needs and concerns of their company in order to produce visionary and dedicated leaders to lead their businesses. For example: a business owner should start out by examining all possible alternatives when making decisions, including the option of doing nothing. Coherent awareness and knowledge in this matter should be established in order to maintain appropriate contingency model that identifies styles of leadership decision making that is useful to the different situations in any working organization [25]. People associated with administration and management in companies must know that decision making process in any organization is somehow complicated and complex in nature.

\section{Major Factors that Influence Leadership Decision Making in Organizations}

This work continues to explore the major factors that influence decision making among organizational leaders. Studies designed to examine the positive challenges of good leadership decision making as an ongoing leadership process [9] may have application to any organizational success and goal attainment in the future. Many studies by different professions had shown that there are several important factors that may influence leadership decision making in organizations. These factors include: past experience [26], cognitive biases [27], age and individual differences belief in personal relevance [28], and an escalation of commitment as well as the influence what choices people make.

People make decisions about many things differently and under different circumstance or situation. For example, a decision about a new product may rest with those in product management, manufacturers, marketing research and finance. They make political decisions personal decisions, including medical choices, romantic decisions, and career decisions; and financial decisions, which may also include some of the other kinds of decisions and judgments. Quite often, the decision making process is fairly specific to the decision being made. Some choices are simple and seem straight forward, while others are complex and require a multi-step approach to making the decisions [29].

Leaders and managers in any organization should weigh all necessary options and the outcomes of their decisions while being aware that each of the decisions made may either affect the organization as a whole, shareholders or any member of the organization. For a sound and comprehensive decision making, leaders should understand that all rational decision making processes requires a great deal of time and a valid sharing or knowledge of information. They should be able to use the best type of leadership decision making style described in Figure 1 to determine the systemic process to apply in any given situation as well as the people or group to be involved in the decision making 
process. Since leadership and management activities in organizations involve change, inspiration, motivation, and influence, management and effective leadership, both leaders and managers must then strive to focus on the process of setting and achieving the goals of their businesses through the functions of management, with reference to strategic planning, organizing, directing, controlling, and goal accomplishments.

Despite the factors mentioned above as well as the ones shown in Figure 2 sometimes, some individual differences may also influence decision making. Research as postulated earlier has indicated that age, socioeconomic status, and cognitive abilities influences decision making [30]. For instance, anger, hatred, divorce, death, and other individual challenges and crises may add to the factors that influence leadership decision making in the workplace and other environments.

However, there are many elements and unavoidable factors that influence the leadership decision making process in many organizations in the society, including who makes the decision and the type of leadership styles (Autocratic, participative, or delegative leadership style) used in making the decision. In this study, the most important factor influencing leaderships in their decision making is the systematic process behind decision-making as well as the ongoing complexities associated with it. These factors are mentioned in Figure 2. These identified major factors are affecting the decisions leaders make in their organizations as well as increasing the wave of challenges and inconsistency among the employees in the workplace. Every organization has the chance of being great and successful when all of the employees work toward achieving its goals. Poor leadership decision making is always associated with chaos and conflicts among working people in organizations. Since leadership is focused on the ability to influence others to accomplish a goal, the researcher believed that the quality of decisions exhibited by organizational leaders is a critical determinant of organizational success. Therefore a good leader must be the one who sees the whole picture rather the particular. $\mathrm{He} /$ she must be the one who organizes the experience of the group, offers a vision of the future, as well as train followers to become leaders [25]. Thus, the understanding of these factors will empower and enable leaders to be creative and effective in choosing from the best alternatives when making decisions for their businesses as well as the establishment of a healthy working environment for everyone in the their companies.

Although some studies have provided significant insight into the factors, constraints, and obstacles influencing decision making among

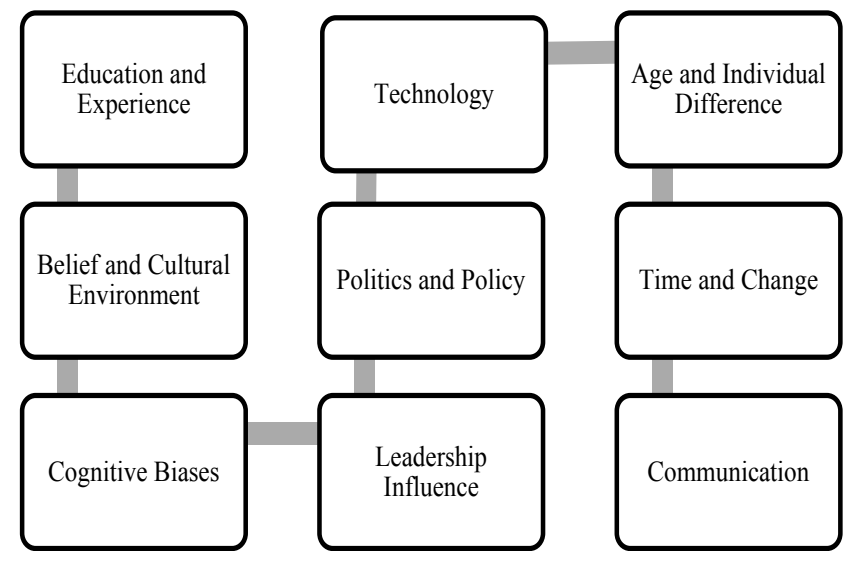

Figure 2: Major factors that influence leadership decision making in organizations. organizational leadership and management in our society, there is still a need for more studies regarding effective leadership decision making, systemic thinking, creativity, dedication, managerial communication, and accountability to enable improvements and leadership capabilities on business leaders and managers. For instance, Sunstein and Thaler [31] stated that a new general strategy for improving biased decision making has been proposed that leverages our automatic cognitive processes and turns them to our advantage [31]. According to Moore and Loewenstein, some research on joint-versus-separate decision making highlights the fact that our first impulses tend to be more emotional than logical. Shiv and Fedorkihn indicated that some additional suggestive results in this domain include the findings that willpower is weakened when people are placed under extreme cognitive load and when they are inexperienced in a choice domain [32].

In like manner, some recent research have shown that some leaders still lack the education, knowledge, quality, and leadership styles associated with sound decision making in their organizations. They either neglect or ignore decision making processes that are aimed at improving the standard of the strategic plans, mission, vision, and goal attainment of their companies. This work is designed to enable leaders and managers to make good decisions for their business as well as to accomplish their organizational goals while remedying the lack of clarity surrounding the construct of some employees and employers participation in the decision making processes. In order to help our current leaders, educate, and train future leaders, the need has been recognized for integrative research which explicitly considers the impact of context on strategic processes [33].

\section{Support of Literature}

The study was aimed at understanding the major factors that influence leadership decision making in organizations. It shows that forms of participation are functional, when a leader has the authority to make decision; when a decision can be made without stringent time limitation; when the subordinate have the relevant knowledge to discuss and implement the decision; as well as when a leader is skilled in the use of participative techniques [34]. To help identify what makes for efficient leadership decision making, a nationwide study of four hundred past and current business executives, leaders, and managements in the United States, participated and identified some factors that influenced their decision making in their respective organizations. This work was based on the perceptions and views of the above selected leaders in discovering the major factors that influence organizational decision making in most businesses across the nation. Making decisions is what leaders and managers do every day in their individual workplace. Thus, apart from individual or group outcomes, leadership decision making is at the heart of virtually all management work and a key driver of organizational outcomes [35-37]. The review of related literatures in this study reveals that leadership decision making in organizations has emerged as one of the most challenging, complex, and active areas of leadership and management future research. Studies of complex social systems suggest that the major reason for (organizational) failure lies in the way decision makers think about and execute the change process [38].

The literature review consists of six main sections, namely: (1) the role of a leader in organizational decision making, (2) understanding the importance of decision-making process, (3) factors influencing leadership decision making, (4) ethics and decision making models, and (5) Communication in decision making.

The literature review enabled the author to identify a resemblance, 
what has been done and what needs to be investigated with regard to the topic. Understanding the process by which leaders and managers make decisions is important to understanding the decisions they make in organization. Effective leaders and managers often provide an encouraging atmosphere to perk up the performance and efficiency of their followers Leiter and Maslach. As already stated, making decisions in organizations is what leaders and managers do every day in their respective business endeavors. While some choices in decision making process may be seen as being simple and easy in thinking, most of the organizational decisions are complex, challenging, time consuming and often require a multi-step approach to making the right needed decisions by leaders. Although many researchers had argued that the size of organizations can be a factor in the decisions their leaders make. For example: Fredrickson and Iaquinto agreed that larger size is associated with comprehensiveness in organizational strategic decision making. More importantly, Dean and Sharfman as well as the Bradford studies [39] found no differences in strategic decision making process that could be attributed to organizational size.

For this researcher, regardless of the nature and size of the organization, leadership decision making is always of vital importance and special significance because they affect the fate of all employees and the entire system in the organization in one way or the other. For instance, identifying critical situations and making quality leadership decisions on that regard, on behalf of the entire organization has been recognized by both organizational and academic investigators as a defining aspect of effective leadership and management processes in businesses. In his opinion, Yukl [5], identified good decision making as one of the key components of leadership strategies in organizational management. All Leaders and other decision makers in companies should understand that a leader is one who can lead a group of people to accomplish common goals in the right direction, with cost efficiency, within the time frame, and achieving the desired outcomes [40].

\section{The Role of a Leader in Organizational Decision Making}

Everyday leaders make decisions. Decision making is the key role of leadership and people always associate leadership in business and politics with making good decisions and a great emphasis on being the head of a group. Leaders must be effective in their organizational decision making by pulling rather than pushing; by inspiring their subordinates rather than ordering them; by enabling people to use their own initiative and experiences rather than by denying their efforts or constraining their experiences and actions in the organization. It of vital importance to know that functional leadership is not usually defined by a specific set of behaviors but instead by generic responses that is prescribed for and will vary by different problem, issues, challenges, circumstances, and different situations. In their views, Hackman and Walton maintained that: the emphasis switches from "what leaders "should do" to "what needs to be done for effective performance" (p. 77). Every organization is a systemic whole and network that is dynamic, challenging, complex in nature, and established for the purpose of serving the common good, and goal accomplishments. While no leader exists and operates outside the organization, all organizations need leaders to exist, and survive in all its operations. According to [14], leaders must know how to lead as well as manage. Otherwise, without leading as well as managing effectively, today's organizations face the threat of extinction.

In the view of Glanz [41], the crux of good leadership is the ability to make thoughtful, reasoned decisions. In order to be the best judge, a leader should have critical thinking skills. They must respond quickly to situations. They must also reflect and be able to point out areas that need improvement. Good judgment in the context of educational leadership requires that the leader have a firm grounding in the educational enterprise, combined with a keen sense of awareness of the complex factors that impinge on school practice. According to Northouse [9] leadership is defined as: "a process where by an individual influences a group of individuals to achieve a common goal" (p. 3). For him, a leader must be willing to take responsibility and tasks, pursue goals, self-confident, exercises initiative in social situations, and willing to accept consequences in all organizational decisions. The paradigm of Northouse, which states that leadership is a process whereby an individual influences a group of individuals to achieve a common goal, clearly focused on the leadership decision making in organizations. It conceptualizes and identifies the five basic elements common to the phenomenon of leadership. These five components include the following elements, and themes that form the core "consensus" components of how leadership is currently conceptualized in the views of Northouse: 1. leadership is a process, 2. leadership emerges out of a reciprocal relationship of influence, 3. leadership occurs in a community or group context, 4 . leadership involves goal attainment around shared visions, purposes, and values, 5. leadership is intentional about making real or concrete change [9].

A greater attention to the above paradigm and five components of organizational leadership and management decisions should provide distinct insight into effective decision making process in all situations. Both employers and employees should know that sometimes mistakes may happen and the important decisions made by intelligent, responsible people with the best information and intentions may go wrong. For instance: the Iraq war and the meltdown of the financial markets in 2008. In such situations, effective leaders are required to acknowledge their mistakes and take the necessary steps to either repair, correct, or amend the situation. For in every organizational activity, constant, clear, and quality leadership is necessary for success $[42,43]$. The way leaders behave and what they choose to do will be judged ultimately by the purpose or motivation of those actions and the values that guide their leadership decisions and behaviors. Leana [44] has found that leader behavior strongly influences the number of alternative solutions proposed and discussed by groups and the actual final decisions made by them. Due to the complexities associated with many organizations, leaders and managers should through sound decision making be able to influence the growth and development of their businesses by bringing in new strategic techniques, technologies, training and development of employees, updating of policies, as well as keeping to the moral standards while maintaining the mission and vision of the organization.

Every business and institutional leader should be held to common standards, with rules and procedures that are clear, firm, fair, and consistent while treating all involved in their company with dignity, prudent, and respect irrespective of their differences. In making good decisions and working effectively well among workers in the organizations, it is necessary that leaders should be deemed as a strategic aim of the organization [45]. However, leaders must have self-confidence, plan ahead, listen, seek correct information, be analytical, and where necessary get their subordinates involved in the decision making process while avoiding not to act in a hurry. There must be a set of steps to incorporate the above elements into a sound decision making process. These elements allow business leaders ability to translate intentions into reality by aligning the energies to the organization behind an attractive goal. As a leader you are expected to make decisions that are in the best interest of the whole organization. 
In affirmation and support of the above statement; Jacobs and Jaques [46] stated:

Executive leaders "add value" to their organizations in large part by giving a sense of understanding and purpose to the overall activities of the organization. In excellent organizations, there almost always is a feeling that the "boss" knows what he is doing, that he has shared this information downward, that it makes sense, and that it is going to work.

\section{Understanding the importance of decision-making process}

A good understanding and the establishment of sound decisions and policies are very important for leadership in all businesses. Leadership is a functional one, meaning that leadership is at the service of collective effectiveness [47-49]. People in leadership positions, be it in institutions, businesses, government, or nonprofit organizations are challenged every day with a myriad of leadership decision making in their individual company. These business leaders and managers are always making decisions that are associated with their subordinates, policy, planning, controlling, methods, training, and compensations do so often in a critical, complex, and challenging situations. Leadership decision-making is an integral part of any organization. It involves a sequence of activities that involves leadership's courage, and evaluation, as well as "gathering, interpreting and exchanging information, creating and identifying alternative courses of action, choosing among alternatives by integrating the often differing perspectives and opinions of team members; and implementing a choice and monitoring its consequences" [50]. As a process of selecting from the many different alternatives, organizational leaders must consider, analyze, and evaluate the best of all different alternatives from which advantages and disadvantages are known. This particular process will help them to make good decisions and enhance the successful operation of their business.

The more skilled leaders are, the more likely they will feel confident in their abilities and competent to make good decisions. For it is only the leader that understands the nature and principles of decision making will be able cope with complex and challenging situations more effectively than the leader who does not possess any of the ideas. For example: the leader who had the knowledge and have studied the qualities and characteristics of organizational diversity stands a better chance of making decision on team building when compared with a leader who have not. Decision making is of vital importance in organization because it permeates through all managerial functions and all areas of business including; recruitment, selection, job description, organizing, planning, training, marketing, policy, and compensation among others. Simply put, it is the act of carrying out managerial tasks and responsibilities. According to Mumford, Zaccaro and Harding [51], problem-solving skills refer to a leader's creative ability to solve new and unusual, ill-defined organizational problems. Nahavandi [40] claims that a leader is anyone who influences individuals or groups within an organization, helps them in the establishment of goals, and guides them toward achievement of those goals, thereby enabling them to be effective.

\section{Factors influencing leadership decision making}

Organizational leadership is the plan the leaders have in place for the organization. They organize a plan in place to establish success and accomplish goals of a company. Decisions are made in organizations daily. These decisions, no matter how big or small, impact organization in a major way. It's important for leaders to evaluate the situation before making a decision. As earlier indicated, many studies by different professions had shown that there are several important factors that may influence leadership decision making in organizations. These factors include: past experience [26], cognitive biases [27], age and individual differences belief in personal relevance [28], and an escalation of commitment as well as the influence what choices people make. Understanding the factors that influence decision making process is important to understanding what decisions are made. That is, the factors that influence the process may impact the outcomes [29]. In like manner, the other major factors that can influence decision making include: leadership style influence, a variety of cognitive biases, change, technology, politics, communication, economic status, market cost, and social responsibility among other factors. The above mentioned factors can affect any organization in one way or the other. Dietrich in discussing leadership decision making strongly agrees that age, environment, socioeconomic status, biases, past experiences are among the relevant factors that influences decision making among organizational leaders and managers.

As mentioned in Figure 1 the three major leadership behavioral styles Kurt Lewin can influence decision making in any organization. There are namely: autocratic, participative, and delegate leadership style. The autocratic also known as authoritative decision making is associated with a leader having a total control and ownership in making decisions in the organization. Here the leader makes decisions with no consultation or suggestion of ideas from his subordinates. This style works well when decisions have to be made quickly and in emergency situations. The participative or democratic style is more inclusive of the group. This is a leadership style that allows and encourages members of the group to express their ideas, and be involved in the decisionmaking process of the organization. The Laissez-faire otherwise known as delegate style allows the leader to delegate the decisionmaking responsibility to an individual or group. This style works well if the leader is surrounded by motivated, skilled and talented group of employees.

The understanding of the culture of the people of any group by a leader is an authentic way of knowing them. Morgan [52] describes culture as an active living phenomenon, through which people jointly create and recreate the world in which they live. The lack of the culture and knowledge of the people in your organization may affect your decision making in your business. The people's culture is very important and what they think ought to be done in their society [53]. Previous experiences can greatly affect future decisions. Juliusson, Karlsson, and Garling [26] also indicated that past decisions may influence the decisions people make in the future.

More recently, some researchers have stressed the importance of environmental, social, and emotional influences on decisionmaking [54-56]. Fischhoff [54] emphasizes the effect that context and interpretation can have on decision-making, and Loewenstern [55] stresses that visceral factors, such as sexual arousal or hunger, can greatly affect decision-making processes. Today, teams and organizations face rapid change like never before. Globalization and technology have increased the markets and opportunities for more growth and revenue. Leadership is human communication which modifies the attitudes and behaviors of others in order to meet shared goals and needs.

\section{Ethics and decision making models}

Ethical codes in organizations are tool for clarifying acceptable behavior and provide guidance to managers when dealing with ethical dilemmas [57]. Ethics is very important in business and each leader 
has an important role to play in ethical decision making in their organizations. Since ethics is defined as the philosophical study of moral behavior, of moral decision making or of how to live the good life. The expectation and common theme for any organizational leader and manager to play in ethical decision making process is dedication, trust, fairness, acting in good faith, and transparency. It is an essential configuration of organizational leadership and management. For instance, it will be of vital importance to have a valid framework in place that would encourage leaders to analyze and make ethical decisions while helping them avoid some complexities and ethical dilemmas in the system that cannot be resolved through the application and implementation of codes of ethics. In this regard, Corey [58] suggested the following ethical decision making model to keep both leaders and decision makers informed in decision making process as well as in the resolution of ethical dilemmas. The model is as follows:

Step 1: Identifytheproblem.

Step 2: Identify the potential issues involved.

Step 3: Review relevant ethical guidelines.

Step 4: Know relevant laws and regulations.

Step 5: Obtain Consultation.

Step 6: Consider possible and probable courses of action.

Step 7: List the consequences of the probable courses of action.

Step 8: Decide on what appears to be the best course of action [58].

The author strongly believed that the above model is of great significant and also maintains that there are some other ethical values that leaders can use to help them better make their decision and serve the value that is most important to them in any given situation. These ethical standards include; integrity, respect, compassion, justice, prudence, temperance, and common good among other things. In order to make a decision in leadership, a thorough explanation requires appealing to a rule, using a theory, and applying a value. This value simply defined is a single word or phrase that identifies something as being desirable for human beings. Values are those goods that our theories, rules, and decisions work to bring about in the world. They (values) are acted on and applied on by theories and then rules [59]. In simple terms, values are not a high-minded code based on personal or company ethics, they are a proposal for creating a work environment that drives accomplishment. Values offer people a framework for their decision, broad limitations for their ideas, and more independence to make a change. In his perspective, Despain [60] postulated that values is defined as shared beliefs with standards for behavior in the workplace, are the key to succeeding in changing and challenging times.

Leaders and managers must have guidelines about what decisions are moral because we have identified certain things as being good, which these decisions seek to uphold. Organizational leaders must possess the following qualities both in leading and decision making in their business:

- Being true to one's basic moral values.

- Involves: honesty, promise keeping, loyalty, dependability and consistency.

- Uphold the dignity of persons; treating them as an ends and not as the means.

- Have concern for the suffering of others and be willing to help out.
- Act on one's professional duties and obligations.

- Able to perform good for people and avoiding harm.

The above principles suggest that leaders must endeavor to do the right thing in their decisions because their subordinates depends to an extraordinary degree on the expressed values of the leader and believe to success by following their leadership decisions. Adherence to ethical standards both in leadership and decision making process must be a foundation of all organizational rules and policies. Macintyre [61] affirmed that virtue is an acquired human quality, the possession and exercise of which enables us to achieve those goods which are internal to practices, and the lack of which prevents us from achieving any such goods. Leadership decision making is about others and not about self. It is about trust and not about power. It is about creating results by generating cultures where people know it is okay to be unique and unlike others, so they freely take off their fronts, express themselves, and do great things. Looking within ourselves and modeling how we think through our own personal and professional ethical code helps shape our teaching and reconfirms what we are teaching in the classroom [62].

\section{Communication in decision making}

A good understanding and the establishment of a valid communication and decision-making are of such significance to leaders and managers in the creation of clear policies in all their individual organizations and businesses. While leadership is a functional one, meaning that leadership is at the service of collective effectiveness [4749] communication in the other hand is arguably one of the single most important aspects of organizational management tool. Communication is the primary function of any effective leader in an organization. In any business operations, valid, effective, and share communication are of great importance to the leaders and manager of every organization. Although organizational leadership has become increasingly complex in both purpose and structure and therefore requires suitable methods of leadership decision systemic styles to address this challenge. One of these suitable methods centers on effective communication and the provision of good working environment.

Communication is one most essential skill that contributes to any successful business. While some of the importance roles of effective leadership in present-day business improvement have been stressed, there is a continuing global debate about the leadership decision making approaches that are most beneficial to maintainable major organizational improvement. It is also useful to be aware that, in today's society, organizational leadership, decision-making, growth, effective management, and organizational success are based on the quality of the decisions policy makers or leaders make Ejimabo [3]. Thus, the establishment of appropriate approach, ways of improving communication, and quality of decision making in any organizations must include the following elements by organizational leaders:

- Appropriate channel for all communications

- Awareness of how perception, culture, channel, and language can create

- Provide a valid working relationship and climate

- $\quad$ Encourage feedback

- $\quad$ Mutual respect and trust

- $\quad$ Promote dialogue and group consensus

- $\quad$ Listen effectively 
- Be clear with words used as intended meaning may be misinterpreted

- $\quad$ Be aware of the culture and diverse nature of the employees

Leadership is all about getting people to work together to make things happen that might not otherwise occur or prevent that which ordinarily would take place. Leaders must cultivate a meaningful relationship in all businesses that requires clear, honest, and reciprocal communication. Leadership position involves motivating others and one way to accomplish this is through a process of sharing information in the system decision making. It is believed that in organizations, leaders have a moral responsibility to take care of their followers and help them develop their personal cares, to be a consultant for followers' personal problems [63]. They must decide on their values and set goals to insure a fruitful decision-making process. Therefore, before making a final decision or taking any course of action, leaders must discover or create a set of alternative courses of action and gather information about each. Having gathered the information with which to make a decision, they must apply information for each course of action to predict the outcomes of each possible alternative and make a decision for implementation [64].

Communication is both complex, irreversible (it is difficult to take back messages that have been sent), and it involves more than just one person sending a message to another. Instead, communication can be seen as the primary defining characteristic of every leader that involves the negotiation of shared interpretations and understanding in the entire organization. Leaders need followers and followers need leaders in order to accomplish the desired goals and outcomes [65-68] in their individual organizations.

\section{Research Questions}

The purpose of this study was aimed at understanding the major factors that influence leadership decision making in organizations. It was focused on identifying what makes for efficient leadership decision making in businesses from the perceptions and views of a nationwide study of four hundred past and current business executives, leaders, and managements in the United States. Decision-making is about facing a question, to be the one you want to be or not to be. The research questions were:

1. How can quality and sound leadership decision making process be improved in major organizational operations?

2. What factors facilitate the implementation of a successful decision making process among leaders in organization?

3. What are the best processes of uncovering strategies to fend off decision-making errors in any organization?

The researcher believed that the answers generated from the above and other related questions that have emerged in the course of this study may provide meaningful and useful insights to organizational leaders and managers in their decision making processes. Organizational decisions are at the heart of leader triumph, and at times there are critical moments when they can be difficult, confounding, and terrifying. However, the bravest decisions are the safest.

\section{Methodology}

The author used the qualitative critical ethnography paradigm in this study to understand the major factors that influence leadership decision making in organizations. The qualitative method places emphasis on understanding through observation, careful documentation, and thoughtful analysis of people's words, actions, and records Creswell [69]. This methodology was based on the experiences of the researcher and the selected participants with the aim of identifying what makes for efficient leadership decision making in organizations. Although the design of a particular business program in San Antonio, Texas and the background and experiences of the investigator set the context of this research. It is important to note that the design and some of the organizational activities in Texas offered the researcher a unique opportunity to effectively examine the role of leader's behavioral styles with reference to leadership activities and decision making in these sittings.

The principal concern in all aspects of this study was to reach some relevant understanding of the major factors that influence sound decision making among leadership and management in businesses as well as to discover an avenue of better solutions to the challenges and complexities associated with decision making in organizations. In this regard, a nationwide data was randomly collected from four hundred past and current business executives, leaders, and managements in some cities and states of the United States. This study was confined to full time organizational leaders, managers with at least seven years' experience in leadership decision making and other leadership activities. With this process, the author was able to gather, not only useful, relevant, and meaningful information, but more importantly, the ability to employ a distinct and analytical techniques in his effort of discovering the major factors that influence leadership decision making in organizations. These made interpretation and understanding of the phenomenon in its context and even beyond, more viable [70].

In this study, the researcher resorted to a critical ethnographic design in this study in order to gain in-depth knowledge and authentic understanding of the issues and problems associated with leadership decision making in businesses. The author was disposed to discovering a pattern of meaning the natural and cultural setting, was interested in the process rather than outcomes, in the context rather the specific variables, and in discovering rather than confirmation [71]. In the views of Denzin and Lincoln a research design is defined as "a basic set of beliefs that guide action' dealing with first principles, ultimate or the researcher's worldviews. The critical ethnographic design was selected in this study because it is seen by many scholars as one of the most effective means of doing comprehensive, systemic, and authentic research. It is also a research method that is located in the practice of both sociologist and anthropologists, and which should be regarded as the product of a cocktail of methodologies that share the assumption that personal engagement with the subject is the key to understanding a particular culture or social setting. Participants' observation is the most common component of this cocktail, but interviews, conversational and discourse analysis, documentary analysis, film and photography, life histories all have their place in the ethnographer's repertoire. Description resides at the core of ethnography, and however that description is constructed it is the intense meaning of social life from the everyday perspective of groups members that is sought [72].

Based on the researcher's judgment and the purpose of the research Babbie, Greig and Schwandt [73-75] and in looking for those who "have had experiences relating to the phenomenon to be researched" Kruger [76], the key participants were limited to the perceptions, experiences and views of 400 hundred past and current business executives, leaders, and managements from some cities and states in the United States. The participants were randomly selected from different cities and states in the country. They consist of 400 hundred full time organizational leaders and managers with at least seven years' experience in leadership 
decision making and other leadership activities, three hundred men, and one hundred women, with an average age of 55 . They also had bachelor degree as their minimum education level, although $55 \%$ of them have master's degree in their professions. The informed consent agreement form and the purpose of the research study were explained to the participants at the beginning of each interview [3].

To achieve these objectives, this study was based upon a qualitative method, duplicating the self-designed survey questionnaire developed from the research questions and discussions from the focus group interviews. The (quantitative) survey data were collected only as a response to the questionnaire and used to support the qualitative data only in the study. It took about 17 months of intensive fieldwork to be designed and executed and can be characterized as a multi-method, in-depth research [77]. The data collection include: (1) individual and semi-structured interview with the selected participants forming twelve groups of different individual leaders, (2) selected leaders and managers useful responses to the research questions, (3) survey data which was collected as a response to the questionnaire and used to support the qualitative data, (4) examining the leadership literatures over the past 12 years, (5) supplementary information from archives with reference to internal documents and reports. All selected individuals and each group participated in two separate interviews to avoid responses being filtered only in the single ideas of a particular interviewee. Here, the investigator chose the researcher's role as an active listener and collaborator "to tell the story from the participants' view rather than as 'expert' who passes judgment on the participants" [78].

According to Creswell, data analysis employed a concurrent nested model. The study followed a sequence of distinct steps in order to secure the reliability of the data based on participant's recall. The qualitative data analysis, which is primarily inductive and recursive process, were analyzed and organized into categories in order to identify themes or patterns as these facilitated a deeper knowledge and understanding of the major factors that influence leadership decision making in businesses. The questionnaire and final survey revisions were made to support and improve the content and process of the data collections, both incorporated qualitative and survey (quantitative) items. Thus, the survey (quantitative) data was systematically organized, analyzed and given a basic descriptive statistical treatment in the study. A follow-up research was conducted by implementing focused interviews of both the selected past and current leaders and managers in different organizations to corroborate the data from the final survey and identify additional variables. The author allowed the selected participants to serve as a check to the study to ensure immediate validation as to the accuracy and credibility of the narratives in the data. The constant communication between the researcher and the selected participants added to the confidence and validity of the interview transcripts [3].

\section{Findings}

The findings are based upon the purpose, objectives, and research questions of this study as well as examined in multiple levels Creswell that include three major sources: (a) open-ended questions posed through interviews, (b) demographics and observation, (c) the survey questionnaire. Based on the research questions, the interview questions were developed thematically. The interview questions helped to provide the structure for data gathering and also served as a means for recording information that was used in this study.

\section{Demographics}

The key participants were limited to the perceptions, experiences and views of 400 hundred past and current business executives, leaders, and managements from some cities and states in the United States. The participants were randomly selected from different cities and states in the country. They consist of 400 hundred full time organizational leaders and managers with at least seven years' experience in leadership decision making and other leadership activities, three hundred men, and one hundred women, with and average age of 55. While 22\% (91) were associated with bachelor degree, 55\% (180) of them had master's degree as their minimum education level, $17 \%$ (68) of them have Ph.D. degree, and $15 \%$ (61) of them had some technical skill (certifications) in their professions. Among these selected participants, 45 of them are the founder of their organizations. All the eligible participants completed the survey and the demographic questions. A general description of the participants shows that they were primarily (75\%) male and (25\%) women with the mean age of 48.25 years old, the mean years of education was 82.75 , and the mean years of work was 46.35 . The position or title of the participants ranged from "President General" (PG) to the "Founder": 130 participants had the leadership rank of president general (32.5\%), 90 of them were "Executive Presidents" (22.5\%), 70 of them had the title of CEO (17.5\%), 65 of them had director positions $(16.3 \%)$, and 45 of them were the founder of their organizations $(11.3 \%)$. There was no data on either race or ethnicity collected. More information on the demographic of the selected participants is shown below in Table 1 . Table 2 shows that majority of the participants (228) used the democratic leadership decision making behavioral style in their businesses. Both men and women tend to use the democratic style when compared to other leadership decision making style. While some leaders (157) associated themselves with autocratic decision making style, only very few leaders (115)

\begin{tabular}{|c|c|c|}
\hline & Number & Percentage \\
\hline $\begin{array}{c}\text { Gender } \\
\text { Male } \\
\text { Female }\end{array}$ & $\begin{array}{l}300 \\
100\end{array}$ & $\begin{array}{l}75 \% \\
25 \%\end{array}$ \\
\hline $\begin{array}{c}\text { Age } \\
25-35 \\
36-44 \\
45-55 \\
56-64 \\
65-75\end{array}$ & $\begin{array}{l}91 \\
84 \\
81 \\
76 \\
68\end{array}$ & $\begin{array}{c}22.7 \% \\
21.5 \% \\
20.3 \% \\
19 \% \\
17 . \%\end{array}$ \\
\hline $\begin{array}{l}\text { Level of Education } \\
\text { Bachelor degree } \\
\text { Technical Skill } \\
\text { Master's degree } \\
\text { Doctoral degree }\end{array}$ & $\begin{array}{c}91 \\
61 \\
220 \\
68\end{array}$ & $\begin{array}{l}22 \% \\
15 \% \\
55 \% \\
17 \%\end{array}$ \\
\hline $\begin{array}{c}\text { Years of Experience } \\
1-5 \\
6-10 \\
11-15 \\
16-20 \\
21-26\end{array}$ & $\begin{array}{l}115 \\
87 \\
75 \\
64 \\
59\end{array}$ & $\begin{array}{l}28.8 \% \\
21.7 \% \\
18.7 \% \\
16.5 \% \\
14.8 \%\end{array}$ \\
\hline $\begin{array}{c}\text { Position/Title } \\
\text { President General } \\
\text { Executive President } \\
\text { CEO } \\
\text { Director } \\
\text { Founder }\end{array}$ & $\begin{array}{c}130 \\
90 \\
70 \\
65 \\
45\end{array}$ & $\begin{array}{l}32.5 \% \\
22.5 \% \\
17.5 \% \\
16.3 \% \\
11.3 \%\end{array}$ \\
\hline
\end{tabular}

Table 1: The demographics of the participants in the study.

\begin{tabular}{|c|c|c|c|}
\hline Gender & Autocratic & Democratic & Delegative \\
\hline Male & 131 & 173 & 96 \\
\hline Female & 26 & 55 & 19 \\
\hline Total & 157 & 228 & 115 \\
\hline
\end{tabular}

Table 2: Leadership decision making style used among participants. 
prefer using the delegative decision making style in their organizations. Table 3 shows the minimum score, maximum score, and means for leadership effectiveness level: Overall, the survey completers seemed to have a good opinion of them based on the survey results. Only one of the result items mean scores was below 4.00 on a 5 -point scale - item 14, "Able to demonstrate patience when the group cannot reach mutually acceptable decisions," which had a mean score of $4.00(S D=1.02)$. The four lowest scored items according the above survey results seem to relate to each other thematically. They include the following items: "Able to cope with the ever changing priorities in our organization" ( $M$ $=4.31, S D=1.10)$; "Show tolerance for diverse opinion" $(M=4.031, S D$ $=0.61)$; "Able to effect career planning and counseling" $(M=4.33, S D$ = 1.03): "Demonstrate appropriate interpersonal relations with team decision making decision making" ( $M=4.38, S D=1.10)$. These items together showed that there are several of the outcomes that may result from a decision are regret or satisfaction; both of which may influence leadership decisions in one way (positive) or the other (negative) in any organizational structure.

In like manner, below are the results of leadership effective items with the four highest scores. These items suggest that the leaders take their roles in organizational decision making seriously in order to achieve their organizational goals and objectives. These items are: "Communicate with the group and individuals appropriately in decision making" ( $M=4.85, S D=0.96)$; "Help the group understand the need to work as a group" $(M=4.77, S D=0.94)$; "Influence others to achieve their goals" $(M=4.62, S D=1.08)$; and "Maintain an appropriate knowledge base" $(M=4.54, S D=1.09)$. In order of vital importance, the following are the major factors the participants in the survey said were both most significant and most frequently relied upon in order to be effective as well as to achieve good decisions in their individual businesses:

1. Demonstrate appropriate interpersonal relations with team decision making decision making.

2. Communicate with the group and individuals appropriately in decision making.

\begin{tabular}{|c|c|c|c|c|}
\hline Leadership effectiveness level & Minimum & Maximum & Mean & SD \\
\hline Able to effect career planning and counseling & 10 & 5 & 4.33 & 1.03 \\
\hline Influence others to achieve their goals & 17 & 5 & 4.62 & 1.08 \\
\hline $\begin{array}{l}\text { Able to understand people and treat them } \\
\text { with respect }\end{array}$ & 14 & 5 & 4.46 & 0.61 \\
\hline Maintain an appropriate knowledge base & 16 & 5 & 4.54 & 1.09 \\
\hline $\begin{array}{l}\text { Help the group understand the need to work } \\
\text { as a group }\end{array}$ & 19 & 5 & 4.77 & 1.26 \\
\hline $\begin{array}{l}\text { Able to appropriately assign tasks and work- } \\
\text { loads }\end{array}$ & 10 & 5 & 4.46 & 0.79 \\
\hline Show tolerance for diverse opinion & 9 & 5 & 4.31 & 0.61 \\
\hline $\begin{array}{l}\text { Demonstrate patience when the group } \\
\text { cannot reach mutually acceptable decisions }\end{array}$ & 5 & 5 & 4.00 & 1.02 \\
\hline Able to explain things to all in a clear way & 16 & 5 & 4.54 & 1.18 \\
\hline $\begin{array}{l}\text { Able to cope with the ever changing } \\
\text { priorities in our organization }\end{array}$ & 9 & 5 & 4.31 & 1.10 \\
\hline $\begin{array}{l}\text { Appreciates the groups confidence in me and } \\
\text { take my leadership position seriously }\end{array}$ & 16 & 5 & 4.54 & 1.07 \\
\hline $\begin{array}{c}\text { Communicate with the group and individuals } \\
\text { appropriately in decision making }\end{array}$ & 21 & 5 & 4.85 & 0.91 \\
\hline $\begin{array}{l}\text { Demonstrate appropriate interpersonal } \\
\text { relations with team decision making decision } \\
\text { making. }\end{array}$ & 11 & 5 & 4.38 & 1.10 \\
\hline $\begin{array}{c}\text { *Note: The above table was designed by the } \\
\text { author. }\end{array}$ & & & & \\
\hline
\end{tabular}

Table 3: The survey results on leadership effectiveness.

\begin{tabular}{|c|c|c|c|}
\hline \multirow[b]{2}{*}{ Behavioral Skill } & \multicolumn{3}{|c|}{ Average Likert-scale scores } \\
\hline & $\begin{array}{l}\text { Priorities for } \\
\text { achievement }\end{array}$ & $\begin{array}{c}\text { Frequently } \\
\text { used }\end{array}$ & $\begin{array}{l}\text { Level of } \\
\text { concerns }\end{array}$ \\
\hline $\begin{array}{l}\text { Demonstrate an understanding of what is } \\
\text { important and what is not }\end{array}$ & 4.6 & 4.5 & 4.8 \\
\hline $\begin{array}{l}\text { Introduce new ideas and approaches to } \\
\text { problems. }\end{array}$ & 4.5 & 4.1 & 4.6 \\
\hline $\begin{array}{l}\text { Take my assigned position in the } \\
\text { organization seriously }\end{array}$ & 4.4 & 4.2 & 4.3 \\
\hline Maintain a confident professional image & 4.4 & 4.3 & 4.3 \\
\hline $\begin{array}{l}\text { Keep people interested in finishing their } \\
\text { assigned tasks }\end{array}$ & 4.3 & 3.9 & 4.0 \\
\hline Being a change agent in the organization & 3.8 & 3.7 & 3.9 \\
\hline $\begin{array}{l}\text { Present new and unique ways of solving } \\
\text { problems }\end{array}$ & 3.6 & 3.6 & 3.3 \\
\hline $\begin{array}{l}\text { Appreciates the groups confidence in me } \\
\text { and take my leadership position seriously }\end{array}$ & 3.2 & 3.0 & 2.7 \\
\hline
\end{tabular}

*Note: The researcher used the Likert-scale values which were as follows:

- The priorities for leaders to achieve their goals in organizational decision making $1=$ not important; $2=$ less important; $3=$ important; 4; very important; $5=$ =ost important

- The frequency used by leaders to perform their individual activity in the organization:

1=not applicable; 2=less applicable; 3=applicable; 4=very applicable; 5=most applicable

The level of concerns of leaders in applying their skills and expertise in organization:

1=not concerned; 2=less concerned; $3=$ =concerned; 4=very concerned; most concerned

Table 4: Behavioral styles of organizational leaders.

\section{Maintain an appropriate knowledge base}

4. Help the group understand the need to work as a group.

The findings indicate support for the factors influencing decision making in the organization. However, the results above (Table 4) really showed how committed and concerned most organizational leaders are in making sure that they make sound decisions in their businesses. For good decisions will always lead to the establishment of good organization. Great leaders always engage in influencing individuals to attain their goals. Individuals are able to contemplate through difficult issues and submit ideas without being swayed by individuals in leadership positions [79]. For him, every leader must make a choice (choosing from among the options), process (electing to make the decision independently or involving others), and purpose (achieving the desired outcome). Thus, the choice a leader makes should be to minimize the negative consequences and maximize the positive outcomes in his/her individual organization. In like manner, the findings in this study were in line with existing research and ideas of Green [79] who believes that individuals and/or groups should be involved in the decision making process when their involvement will enhance the quality and/or acceptance of the decision.

\section{Discussions}

The purpose of this study was aimed at understanding the major factors that influence leadership decision making in organizations. This part of work presents the discussion of results and incorporates related literature in identifying a pattern of meaning in this study. There are four main themes that emerged in this research, namely: (1) listening skills, (2) good communication, (3) interpersonal relation with teams, and (4) trust and dialogue. The discussion of these themes was meant 
to enable the organizational leaders to better understand the process of decision making as it affects the employees in their organizations. The stories and experiences of the focus group were the tools and elements used in order to discover a pattern of meaning and achieve result. In the views of the participants, most of them commented on the need to consider the complexities and unpredictability that are associated with decision making in organizations. Evidently, the roles of the participants could be seen in most of what some of them shared with the researcher. For instance, one of the Participants stated that:

Leaders make decisions based on data, experience and influence. In my 22 years leadership experience, I do sincerely think that creative leaders must be willing to listen to their subordinates in order to make the best decision .... For me, valid communication is always the key to success. Having a two way communication will enhance the team's effectiveness in positive leadership decision making in any business (Participant XXX142, February, 2014).

In the present challenging world, the leadership decision making process can be complicated and overwhelming in almost all businesses. As a result, it is valuable for organizational leaders to be educated in technology, cultural diversity, ethical standards to enable them learn the best model to follow, that may be applied to everyday decisions, as well as life changing choices in their individual businesses. Leadership needs to be looked at as an exercise rather than as a role. Most of them also agree to the usefulness of the Lewin leadership approaches namely: autocratic, democratic, and laissez-faire methods of leadership decision making processes in the context of this study.

For others, in sharing their knowledge, stories, and experiences as leaders and decision makers in their businesses expressed great concerns about the factors that influence leadership decision making and leaders' behavioral styles. They all agree that leadership and management activities in organizations involve change, inspiration, motivation, influence, management and effective leadership. They also, suggested that both leaders and managers must strive to focus on the process of setting and achieving the goals of their businesses through the functions of management, sharing of valid information among groups, and maintaining a positive status quo with the aim of accomplishing a goal. In that regard, one of the participants said:

.... You gain strength, courage, and confidence by every experience in which you really stop to look fear in the face. Wherever you see a successful business, someone once made a brave decision. The struggle in life is the choice ... and then we make our real decision for which we are responsible. ... (Participant XXX095, July, 3013).

The interviews and discussions with some of the participants in this study revealed that most of them are highly educated in their individual profession but fail to appreciate their groups' confidence and effort in their positions as executive leaders in the organization. Furthermore, some of them think only about their positional power and not what they can achieve by working as a team with their subordinates. They impose their power (authority) on their subjects while dictating to them what to do in the organization without involving them in any decision making. This study argues that group dynamics and participative leadership behavioral style in decision making is of vital relevance and significance in any organizational decision making. Most employees are more comfortable when included or allowed to participate in the organization decisions. According to Participant XXX 023 (March, 2013) he stated:

...openness to dialogue and positive sharing of meaningful ideas and experiences in making organizational decision is useful. It allows creative and more experienced workers to contribute their rich ideas and valuable knowledge ... to the decision making process.

While decision making is at the root of all we do, it is useful for leaders and manager to develop effective decision making skills and strategies in their organizations. More importantly, openness of communication and the ability to allow creative shared information at workplace can always encourage worker's job satisfaction. Problem solving strategies include, but are not limited to brain storming, cost benefit analysis, written remediation plans, and an examination of possible choices [80].

\section{Conclusion}

The purpose of this qualitative critical ethnographic study was focused on identifying the factors influencing success in decision making among organizational leaders and managers in organizations' practices. This study examined the influence of decision making in organizational leadership and management activities that impact creativity, growth and effectiveness, success, and goal accomplishments in current organizations. The author being committed and determined to discovering a pattern of meaning focused on identifying the major factors that influence success in decision making process among organizational leaders through the views and experience of the selected participants in this study. They indicated the importance and urgent need towards the understanding of how leaders arrive at their choices in their leadership decision making process.

In the views of the participants, they all agreed that leadership decision making are one of the most dynamic, challenging, and ongoing concept in every organization. They affirmed that leaders and managers of all levels should consider the general interest of the people they are serving in their decisions while encouraging effectiveness. Findings indicated that there is a great need for change and improvement in decision making among organizational executives while accommodating technology, diversity, globalization, policy, teamwork, and leadership effectiveness. The answers generated from both the research and the interview questions really contributed, provided a meaningful and useful insights to this study. Finally, decision making in organization is an ongoing process. In that regard, there is need for future research on leadership decision making. Thus, the leadership ability to understand the factors that influence decision making process in their business is important and a major key to understanding what decisions are made for the progress of the organization.

\section{Recommendations}

1. It is valuable for leaders to be educated in technology, cultural diversity, and ethical standards to enable them learn the best model to follow in their leadership decision making process.

2. Leaders must cultivate a meaningful relationship in all businesses that requires clear, honest, and reciprocal communication.

3. Leaders must have self-confidence, plan ahead, listen, seek correct information, be analytical, and where necessary get their subordinates involved in the decision making process while avoiding not to act in a hurry.

4. Leaders must know what decisions to make and keep the interest of all stakeholders involved.

5. They must show followers that they are able to acknowledge when they are wrong and move forward to a better solution.

6. There is a great need for future research on this matter "Leadership decision making process. 
Citation: Ejimabo NO (2015) The Influence of Decision Making in Organizational Leadership and Management Activities. J Entrepren Organiz Manag 4: 138. doi:10.4172/2169-026X.1000138

Page 12 of 13

\section{References}

1. Hsiung H (2012) Authentic Leadership and Employee Voice Behavior: A MultiLevel Psychological Process. Journal of Business Ethics 107: 349-361.

2. Olsen EE, Eoyang GH (2001) Facilitating organization change: lessons from complexity science. Jossey Bass, San Francisco, CA.

3. Ejimabo NO (2013) Understanding the impact of leadership in Nigeria: its reality, challenges, and perspectives. Sage Open 1-14

4. Nelson D, Quick J (2003) Organizational behavior: Foundation, realities, and challenges. Mason $\mathrm{OH}$ : Thomson Southwestern.

5. Yukl G (2010) Leadership in Organizations (7thedn.) Prentice Hall.

6. Stogdill RM (1974) Handbook of leadership: A survey of theory and research. Free Press, New York.

7. Glaholt MG, Wu MC, Reingold EM (2010) Evidence for top-down control of eye movements during visual decision making. Journal of Vision 10.

8. Yukl G, Lepsinger R (2005) Why integrating the leading and managing roles is essential for organizational effectiveness. Organizational Dynamics 34: 361 375.

9. Northouse PG (2004) Leadership: Theory and practice (3rdedn.) Sage, Thousand Oaks, CA.

10. Drath W, Palus CJ (1994) Making common sense: Leadership as meaningmaking in a community of practice. Center for Creative Leadership, Greensboro, NC.

11. Jacobs TO, Jaques E (1990) Military executive leadership. In: Clark KE, Clark MB (eds.) Measures of leadership. Leadership Library of America, West Orange, New Jersey pp: 281-295.

12. Pomerol JC, Adam F (2004) Practical decision making-From the legacy of Herbert Simon to Decision Support Systems. In: Decision Support in an Uncertain and Complex World: The IFIP TC8/WG8.3 International Conference 2004. Symposium conducted at The IFIP TC8/ WG8.3 International Conference, Monash University.

13. Langley A, Mintzberg H, Pitcher P, Posad E, Saint-Macary J (1995) Opening up decision making: The view from the black stool. Organization Science 6: 260-279.

14. Kotter JP (1990) A Force for Change: How leadership differs from management The Free Press, New York, USA.

15. Thomas GF, Zolin R, Hartman J (2009) The Central Role of Communication In Developing Trust and its Effect on Employee Involvement. Journal Of Business Communication 46: $287-310$

16. Marrow AJ (1969) The Practical Theorist: The Life and Work of Kurt Lewin Basic Books Inc., New York.

17. Likert R (1947) Kurt Lewin: a pioneer in human relation research. Human Relations 1: 131-140.

18. Cummings TG, Huse EF (1989) Organization Development and Change (4thedn.) West Publishing, St. Paul MN.

19. Burnes B (2000) Managing Change (3rdedn.) FT/Pearson Educational, Harlow.

20. Dawson P (1994) Organizational Change: A Processual Approach. Paul Chapman Publishing, London.

21. Dent EB, Goldberg SG (1999) Challenging resistance to change. Journal of Applied Behavioral Science 35: 25-41.

22. Hatch MJ (1997) Organization Theory: Modern, Symbolic and Postmodern Perspectives. Oxford University Press, Oxford

23. Kanter RM, Stein BA, Jick TD (1992) The Challenge of Organizational Change. Free Press, New York.

24. Marshak RJ (1993) Lewin meets Confucius: a re-view of the OD model of change. The Journal of Applied Behavioral Science 29: 393-415.

25. Boone, Bowen D (1987) The great writing in management and organizational behavior. Random House Inc., New York.

26. Juliusson EA, Karlsson N, Gärling T (2005) weighing the past and the future in decision making. European Journal of Cognitive Psychology 17: 561-575.

27. Stanovich KE, West RF (2008) On the relative independence of thinking biases and cognitive ability. Journal of Personality and Social Psychology 94: 672-695.

28. Acevedo M, Krueger JI (2004) Two egocentric sources of the decision to vote: The voter's illusion and the belief in personal relevance. Political Psychology 25: $115-134$

29. Dietrich M (2010) Efficiency and profitability: a panel data analysis of UK manufacturing firms 1993-2007.

30. Finucane ML, Mertz CK, Slovic P, Schmidt ES (2005) Task complexity and older adults' decision-making competence. Psychology and Aging 20: 71-84.

31. Sunstein CR, Thaler RH (2003) Libertarian paternalism is not an oxymoron University of Chicago Law Review 70: 1159-1199.

32. Milkman KL, Rogers T, Bazerman M (2008) Harnessing your inner angels and demons: What we have learned about want/should conflict and how that knowledge can help us reduce short-sighted decision making. Perspectives on Psychological Science.

33. Bateman TS, Zeithami CP (1989) The psychological context of strategic decisions: A model and convergent experimental findings. Strategic Management Journal10: 59-74

34. Kerr J, Slocum JW Jr (1987). Managing corporate culture through reward systems. Academy of Management Executive 1: 99-108.

35. Barnard Cl (1968) The functions of the executive. Harvard University Press, Cambridge MA.

36. Donaldson G (1983) Decision making at the top: The shaping of strategic direction. Basic Books, NewYork.

37. Finkelstein S, Hambrick D (1996) Top management team tenure and organizational outcomes: The moderating role of managerial discretion. Administrative Science Quarterly 35: 484-503.

38. Smith LT (1999) Decolonizing methodologies: Research and indigenous peoples. University of Otago Press, Dunedin, New Zealand.

39. Hickson CJ (1986) Quaternary volcanics of the Wells Gray-Clearwater area. East central British Columbia: Ph.D. Thesis, University of British Columbia Vancouver.

40. Nahavandi A (2004) The art and science of leadership (4thedn.) Pearson Education, Upper Saddle River, NJ.

41. Glanz J (2002) Finding your leadership style: A Guide for Educators. Association for Supervision and Curriculum Development, Alexandria VA.

42. Everett C (2002) Penn States commitment to quality improvement. Quality Progress 35: 44-49.

43. Buch K, Rivers D (2002) Sustaining a quality initiative. Strategic Direction. 18 15-17.

44. Leana CR (1985) A partial test of Janis' groupthink model: Effects of group cohesiveness and leader behavior on defective decision-making. Journal of Management 11: 5-17.

45. Feigenbaum A (1991) Total quality control (3rdedn.) McGraw-Hill, NY

46. Jacobs TO, Jaques E (1991) Executive leadership. In: Gal R, Manglesdorff AD (eds.) Handbook of military psychology, Wiley, New York.

47. Fleishman EA, Mumford MD, Zaccaro SJ, Levin KY, Korotkin, AL, et al. (1991) Taxonomic efforts in the description of leader behavior: A synthesis and functional interpretation. Leadership Quarterly 2: 245-287.

48. Hackman JR, Walton RE (1986) Leading groups in organizations. In Goodman PS (ed.) Designing effective work groups. Jossey-Bass, San Francisco.

49. Lord RG (1977) Functional leadership behavior: Measurement and relation to social power and leadership perceptions. Administrative Science Quarterly 22 114-133.

50. Thompson LL (2008) Making the Team: A guide for Managers (3rdedn.) Prentice, NJ.

51. Mumford MD, Zaccaro SJ, Harding EA (2009) The leadership. Quarterly Newsletter 11: 155-170.

52. Morgan G (1997) Images of Organization. Sage Publications, Thousand Oaks CA.

53. Hofstede GH (2001) Culture's consequences: Comparing values, behaviors, institutions, and organization across nations (2ndedn.) Sage, Thousand Oaks, CA. 
Citation: Ejimabo NO (2015) The Influence of Decision Making in Organizational Leadership and Management Activities. J Entrepren Organiz Manag 4: 138. doi:10.4172/2169-026X.1000138

54. Fischhoff B (1996) The real world: what good is it? Organizational Behavior and Human Process 65: 232-248.

55. Moore D, Lowenstein G (2004) Self-interest, automaticity, and the psychology of conflict of interest. Social Justice Research 17: 189-202.

56. Strack F, Neumann R (1996) "The spirit is willing, but the flesh is weak": beyond mind-body interactions in human decision-making. Organizational Behavior and Human Process 65: 272-292.

57. Lewis CW (1991) The ethics challenge in public service--A problem solving guide. Jossey-Bass, SanFrancisco, CA.

58. Corey G, Corey M, Haynes R (1998) Student workbook for Ethics in Action. Brooks, Pacific Grove, CA.

59. Brincat CA, Wike VS (2000) Morality and the Professional Life: Values at Work. Prentice Hall Inc.

60. Despain JE (2003) And dignity for all: unlocking greatness through valuesbased leadership. Upper Saddle River: Pearson Education.

61. Macintyre AC (1981) After virtue. University of Notre Dame Press, San Francisco, CA.

62. Shapiro JP (2005) Ethical leadership and decision making in education: applying theoretical perspectives to complex dilemmas. Lawrence, Mahwah.

63. Bass BM (1995) Theory of transformational leadership redux. Leadership Quarterly 6: 463-478.

64. Deutsch M, Coleman PT (2000) The Handbook of Conflict Resolution Theory and Practice (eds.) Jossey-Bass Publishers, San Francisco.

65. Burns JM (1978) Leadership. Harper and Row, New York, NY.

66. Heller T, Van Til J (1983) Leadership and followership: Some summary propositions. Journal of Applied Behavioral Science Volume 18: 405-414.

67. Hollander EP (1992) Leadership, followership, self, and others. Leadership Quarterly 3: 43-54.
68. Jago AG (1982) Leadership: Perspectives in theory and research. Management Science 28: 315-336.

69. Creswell JW (2003) Research design: Qualitative and quantitative, and mixed method approaches. Sage, Thousand Oaks, CA.

70. Mertens DM (1998) Research methods in education and psychology: Integrating diversity with quantitative and qualitative approaches. Sage, Thousand Oaks, CA.

71. Unknown Author (2015) The meaning of leadership decision making. Retrieved from (http://www.merriam-webster.com/dictionary/decision).

72. Hobbs D (2006) Ethnography. In: Jupp V (ed.) The Sage Dictionary of Social, Research Method. Sage, Oxford, UK, pp. 25-38.

73. Babbie E (1995) The practice of social research (7thedn.) Wadsworth, Belmont CA.

74. Greig A, Taylor J (1999) Doing research with children. Sage, London, UK.

75. Schwandt TA (1997) Qualitative inquiry: A dictionary of terms. Sage, Thousand Oaks, CA.

76. Kruger D (1988) An introduction to phenomenological psychology (2ndedn.) Juta, Cape Town, South Africa.

77. Snow CC, Thomas JB (1994) 'Field Research Methods in Strategic Management: Contributions to Theory Building and Testing'. Journal of Management Studies 31: 457-448.

78. Creswell JW (1998) Qualitative research and design: Choosing among five traditions. Sage, Thousand Oaks, CA.

79. Green LR (2013) Practicing the art of leadership. Pearson education Inc. Upper Saddle River, NJ.

80. Wester SR, Christianson HF, Fouad NA, Santiago-Rivera AL (2008) Information processing as problem solving: A collaborative approach to dealing with students exhibiting insufficient competence. Training and Education in Professional Psychology 2: 193-201. 